\title{
Induction of an Anthranilate Oxidation System During the Metabolism of ortho-Nitrobenzoate by Certain Bacteria
}

\author{
By R. B. CAIN* \\ Department of Biochemistry, University of Leeds, and Department of \\ Microbiology, Oklahoma State University, Stillwater, Oklahoma, U.S.A.
}

(Received 11 May 1965, accepted 16 September 1965)

\begin{abstract}
SUMMARY
Nocardia opaca, a flavobacterium and certain other bacteria, when grown on $o$-nitrobenzoate, accumulated anthranilate in the medium in the early stages of growth. The subsequent disappearance of this metabolite in growing cultures was always correlated with the appearance of an anthranilate oxidase system in the organisms. This phenomenon has the features of a typical enzyme adaptation except that the inducer is a byproduct of the cells' own metabolism; hence it has been termed 'metabolite induction'. The results confirm previous suggestions that, in these micro-organisms, anthranilate is not an obligatory intermediate in the direct energy-producing pathway of $o$-nitrobenzoate breakdown but is produced in a side reaction.
\end{abstract}

\section{INTRODUCTION}

Previous work (Cain, 1958; Cartwright \& Cain, 1959a, b) showed that the $p$ and $m$-aminobenzoic acids are not intermediates on the direct pathway of oxidative degradation of the corresponding nitrobenzoic acid isomers by nocardia species, but are produced by a reductive side reaction which operates concurrently (Cain \& Cartwright, 1960 b). At that time the situation in Nocardia opaca with regard to the o-isomer was not clear though $\mathrm{Ke}$, Gee \& Durham (1959) had found that growth of a flavobacterium on 0 -nitrobenzoate did not sequentially induce the enzymes to oxidize anthranilate. During the metabolism of $o$-nitrobenzoic acid by $N$. opaca, marked variations were often observed in the rates of oxidation of anthranilic (o-aminobenzoic) acid, a possible intermediate in the oxidative degradation of the nitro compound. Such variations appeared to depend on the time at which the organisms had been harvested from growing cultures. Closer examination of these changes showed that the bacteria developed the ability to oxidize anthranilic acid as it appeared in the culture medium from reduction of $o$-nitrobenzoic acid, and thereafter lost this ability progressively until it eventually almost disappeared as the anthranilic acid was used up. Oxidative attack on the $o$-nitrobenzoic acid substrate continued during these events. Since $N$. opaca oxidizes both $o$-nitrobenzoic acid and anthranilic acid, after growth on these respective substrates, through catechol (Cartwright \& Cain, 1959 $a$; Cain \& Cartwright, 1960 $a$; Cain, 1966), it was obvious that these variations in anthranilic-oxidizing activity would influence the interpretations of results obtained with the 'simultaneous adaptation' (sequential induction) technique (Stanier, 1947). The present paper describes the nature of

* Present Address: Department of Botany, The University, Newcastle upon Tyne, 1. 
these enzymic variations and adds further evidence for the original contention that in nocardia the aminobenzoates are not obligatory intermediates in the aerobic energy-yielding pathway of nitrobenzoate degradation.

\section{METHODS}

The organisms used in this study were strain 06 of Nocardia opaca (Cain, 1958); an organism iwhich was isolated by elective methods on anthranilic acid from local soil in Oklahoma and later identified as a nocardia species; the flavobacterium used by Durham (1958); a pseudomonas isolated from soil by elective culture with $o$-nitrobenzoic acid.

All organisms grew equally well with $o$-nitrobenzoic acid or anthranilic acid as the sole source of carbon, nitrogen and energy. The Oklahoma organism differed from the other bacteria used in that it did not produce the deep reddish-brown coloration in the medium characteristic of growth of the other organisms on $o$-nitrobenzoate and anthranilate.

Cultures were grown at $30^{\circ}$ with forced aeration (about $2 \mathrm{l}$. sterile air/min.) through a sintered glass distributor in 4 or 5 l. flasks fitted with a sterile sampling device. The flasks contained the following defined medium (g./l.): organic source, $1.0 ; \mathrm{KH}_{2} \mathrm{PO}_{4}, 0.5 ; \mathrm{MgSO}_{4} .7 \mathrm{H}_{2} \mathrm{O}, 0.1$; trace elements solution (Barnett \& Ingram, 1955) $10 \mathrm{ml}$./l. medium; in cases where the organic compound did not provide a source of nitrogen $\left(\mathrm{NH}_{4}\right)_{2} \mathrm{SO}_{4}(0.5 \mathrm{~g}$. $/ \mathrm{l}$.) was added to the defined medium. 'Marmite' (a British edible yeast extract preparation) or Difco yeast extract, was added to the medium $(0.02 \%, w / v)$ only where indicated. The medium was adjusted to $\mathrm{pH} 7 \cdot 0-7 \cdot 2$.

Cultures (5l.) were started with a 48-hr $100 \mathrm{ml}$. inoculum grown in Erlenmeyer flasks and after visible growth had begun, samples were removed aseptically at intervals, the organisms harvested by centrifugation at $4^{\circ}$, washed once with icecold distilled water and their activity towards anthranilic and $o$-nitrobenzoic acids examined without delay (usually within $1 \mathrm{hr}$ from sampling) in the Warburg respirometer with air as the gas phase. Enzyme activities were expressed as $\mathbf{Q}_{\mathbf{O}_{2}}$ ( $\mu \mathrm{l} . \mathrm{O}_{2}$ uptake/hr/mg. dry wt. organism), oxygen uptakes being measured in air at 5 min. intervals from 0 to $30 \mathrm{~min}$. at $30^{\circ}$ in flasks containing $200 \mu$ moles phosphate

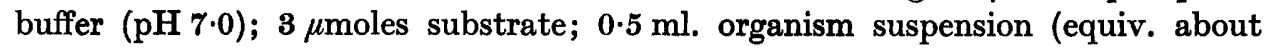
$5 \mathrm{mg}$. dry-wt. organism); $0 \cdot 2 \mathrm{ml} .20 \% \mathrm{KOH}$ in the centre well; total volume to $3.0 \mathrm{ml}$. with water. Duplicate experimental vessels and a control (no substrate) were run for each sample. The absence of continued enzyme induction in the presence of anthranilic acid in the Warburg vessels was shown by the linear oxygen uptakes observed during the first 20-30 min. In confirmatory experiments possible subsequent enzyme induction was prevented by irradiating the suspensions with ultraviolet radiation or by incubating the washed organisms for $30 \mathrm{~min}$. with D-threochloramphenicol $(10 \mu \mathrm{g} \cdot / \mathrm{ml}$. final concentration) in the Warburg vessels before tipping the substrate. D-threo-chloramphenicol did not alter the existing degree of activity of the anthranilate-oxidizing system up to a concentration of $20 \mu \mathrm{g} . / \mathrm{ml}$. All three methods gave similar results. Dry-weights of organisms were the mean of duplicate $3 \mathrm{ml}$. samples of suspensions dried at $105^{\circ}$ to constant weight on aluminium planchets. The manometric method was used to ensure a measure of 'anthranilic 
oxidase' (Higashi \& Sakamoto, 1960) in organisms where anthranilic acid may also be converted to other products not involved in the oxidative pathway (Cain \& Cartwright, 1960b).

Anthranilic acid was estimated by diazotization (Glazko, Wolf \& Dill, 1949) and $o$-nitrobenzoic acid by the quantitative chromatographic method used originally with the $p$-isomer (Cain, 1958). Where $o$-nitrobenzoic acid and anthranilic acid were present together in similar amounts, their respective concentrations could be calculated from their molecular extinctions at 268 and $240 \mathrm{~m} \mu$ by solving the simultaneous equations provided by direct measurement, on suitably diluted samples, of the extinctions of the test solution at these wavelengths. At $\mathrm{pH} \mathrm{7.0} \mathrm{in} \mathrm{0.1} \mathrm{M-}$ phosphate buffer, the values are: 0 -Nitrobenzoic acid: at $240 \mathrm{~m} \mu, \epsilon=2185$; at $268 \mathrm{~m} \mu, \epsilon=3120$. Anthranilic acid: at $240 \mathrm{~m} \mu, \epsilon=4505$; at $268 \mathrm{~m} \mu, \epsilon=310$. Nocardia opaca did not reduce the aromatic nitro group of chloramphenicol (Cartwright \& Cain, 1959 $b$; and unpublished results) so the presence of this compound in culture media did not affect estimations of arylamines by the diazotization procedure.

The growth of cultures was measured turbidimetrically at $530 \mathrm{~m} \mu$ with the Bausch and Lomb 'Spectronic 20' or the Beckman DU spectrophotometer; extinction readings were calibrated against dry-weight measurements for the appropriate organisms where required. Because the growth of Nocardia opaca and the flavobacterium results in the production of a deep reddish-brown coloration of the medium, it was necessary to observe the precautions detailed previously (Cain, 1958) in making extinction measurements in cultures of these organisms. The approximate generation times of these organisms in $o$-nitrobenzoic acid medium supplemented with yeast extract were: $N$. opaca, $3.5 \mathrm{hr}$; the flavobacterium, $1.5 \mathrm{hr}$; the Oklahoma isolate, $3.8 \mathrm{hr}$, the pseudomonad, $1.5 \mathrm{hr}$.

Ultraviolet irradiated organisms were obtained by suspending the organisms (in water) as a shallow layer in a flat-bottomed Petri dish"and exposing at $15 \mathrm{~cm}$. from a General Electric germicidal U.V. lamp (30 watts; predominant wavelength $254 \mathrm{~m} \mu$ ) for $5 \mathrm{~min}$.

The fluctuation test of Luria \& Delbrück (1943) was modified to suit the present system as follows. Fifteen test-tubes $(15 \times 230 \mathrm{~mm}$.) were set up, each containing $1 \mathrm{ml}$. of the defined medium with $o$-nitrobenzoic acid as the only organic substrate. A large boiling tube and a $100 \mathrm{ml}$. Erlenmeyer flask each contained $15 \mathrm{ml}$. of the same medium, the tube and flask diameters being so chosen that the depth of medium therein was similar to that of the $1 \mathrm{ml}$. samples. After sterilization and cooling, all these tubes and flasks were inoculated with $5 \times 10^{3}$ Nocardia opaca organisms $/ \mathrm{ml}$. previously grown on 0 -nitrobenzoic acid medium, harvested in the log phase of growth and washed twice with sterile distilled water using aseptic precautions. The culture tubes were then incubated for $24-48 \mathrm{hr}$ at $30^{\circ}$ on a reciprocating shaker (throw $8 \mathrm{~cm}$.; shake speed 94 strokes $/ \mathrm{min}$.) to increase aeration. Non-aerated cultures gave very erratic growth. At the end of the incubation period the contents of the $1 \mathrm{ml}$. test tubes were poured and spread on plates of anthranilic acid defined medium solidified with $2 \%(w / v)$ washed agar. The plates of anthranilic acid medium were incubated at $30^{\circ}$, the appearance of resulting colonies being observed at intervals thereafter. Additional 1 and $15 \mathrm{ml}$. cultures were always run for determination of anthranilate formation and for total viable count made on suitable dilutions on nutrient agar. 
When the concentration of anthranilic acid, arising from o-nitrobenzoic acid reduction during growth of Nocardia opaca in the culture tubes, became appreciable before plating on anthranilic acid medium, however, the number of colonies which appeared on the plates was not a true measure of the possible anthranilic acidutilizing mutants originally occurring in the 0 -nitrobenzoate culture. Such mutants, if they exist, would have already been undergoing selection and growth in the anthranilic acid-containing environment. Cultures were always plated, therefore, before appreciable amounts of anthranilic acid had appeared. In the experiments described, the anthranilic acid was always below $2 \mu \mathrm{g} . / \mathrm{ml}$. (14 $\mu \mathrm{M})$ at which concentration development of an anthranilate oxidase was never observed in growing cultures. In the experiment illustrated in Table 4, this concentration was less than $0.5 \mu \mathrm{g} . / \mathrm{ml} .(3.5 \mu \mathrm{M})$.

Replica plating from cultures on nitrobenzoate medium to anthranilate medium was done by the velvet pad method of Lederberg \& Lederberg (1952). Replication was made from the master plate while the colonies were barely visible.

The chemicals used were of commercial origin. Technical grade anthranilic acid was decolourized with activated charcoal, and re-crystallized three times from ethanol + water before use in growth media or manometric experiments. The $\mathrm{N}$ methylanthranilic acid and the $o$-aminobenzensulphonic acids (supplied by Eastman Organic Chemicals) were also recrystallized, after charcoal treatment, to yield off-white crystals. In spite of several recrystallizations from ethanol + water and ethyl acetate + benzene, $N$-methylanthranilic acid was not completely freed from anthranilic acid, as shown by chromatography and colorimetric analysis; $1 \mathrm{mg}$. of recrystallized $N$-methylanthranilic acid still contained 6.1 $\mu \mathrm{g}$ anthranilic acid as determined by the Bratton-Marshall procedure (Glazko et al., 1949); since the primary amino group is alkylated, the $N$-methylanthranilic acid does not react in this test.

Chromatography of the nitro- and amino-benzoic acids was done by the ascending technique on Whatman No. 1 paper with the following solvent systems (all proportions by volume); (A) ethanol+ammonia (sp.gr. $0 \cdot 88)+$ water $(80+4+16)$; (B) $n$-butanol + glacial acetic acid + water $(4+1+5)$. The compounds were detected under u.v. radiation, anthranilic acid and its derivatives by their blue fluorescence and $o$-nitrobenzoic acid by its quenching. D-threo-chloramphenicol and the biologically inactive L-threo isomer were the products of Parke Davis \& Co. and were provided by Dr E. A. Grula.

Nomenclature. The anthranilate oxidizing system in intact organisms will be referred to in this paper as 'anthranilate oxidase'. The term oxidase is nowadays strictly used only for enzymes catalysing a reaction where oxygen is an acceptor of protons from the substrate. Taniuchi et al. (1964) have shown that the overall reaction in a pseudomonad is

$$
\text { anthranilate }+\mathrm{O}_{2}+\mathrm{NADH}+\mathrm{H}^{+} \rightarrow \text { catechol }+\mathrm{CO}_{2}+\mathrm{NAD}^{+}+\mathrm{NH}_{3}
$$

in which both oxygen atoms have actually entered the molecule. They have given their partially pure enzyme the trivial name anthranilic hydroxylase. For brevity and to conform with previous descriptions of impure systems (e.g. Higashi \& Sakamoto, 1960) 'anthranilate oxidase' is used here to describe the system which metabolizes anthranilate with the simultaneous utilization of oxygen. 


\section{RESULTS}

\section{Variations in enzyme concentration in organisms grown with o-nitrobenzoic acid}

Batches of yeast extract-enriched $o$-nitrobenzoate media (5 l.) at $30^{\circ}$, inoculated with $50 \mathrm{ml}$. of a log phase culture of Nocardia opaca, were sampled at 3-hr intervals after visible growth had appeared (12-15 hr), and the $Q_{\mathrm{O}_{2}}$ of the organisms with anthranilate as substrate and the concentration of this metabolite in the medium were measured. Figure 1 shows that after an initial increase in anthranilate concentration, the subsequent disappearance of anthranilate was correlated with the appearance of a marked ability of the organisms to oxidize this substrate and also that the anthraniliate oxidizing activity decreased as anthranilate disappeared. Such a pattern was repeatedly confirmed with this organism. A similar ready loss of the inducible enzyme system for $o$-nitrobenzoate oxidation in $N$. opaca (Cain, 1958) also occurred upon the exhaustion of the available substrate. It is obvious that in this particular case, the time of sampling would appreciably alter the conclusions to be drawn from sequential induction experiments regarding the significance of anthranilic acid as an intermediate in $o$-nitrobenzoate acid oxidation. In contrast, organisms grown on succinate showed a typical adaptive response to both anthranilate and $o$-nitrobenzoate, irrespective of the time of harvesting. Both the time of appearance and the maximum levels of the induced anthranilate oxidase varied in different experiments according to size of inoculum and aeration rate but anthranilate oxidase rarely appeared before $22-24 \mathrm{hr}$; the peak of the activity occurred between 33 and $40 \mathrm{hr}$ after inoculation with $N$. opaca.

The variations in enzyme concentration in the four bacteria tested were similar. Nocardia opaca and the Oklahoma isolate generally showed a maximum $Q_{\mathrm{O}_{2}}$ of 35-40 for the metabolite-induced anthranilate oxidase but occasional maximum values as low as 15 were recorded. The flavobacterium also showed an adaptive response as a result of the very marked decrease in anthranilic acid concentration at $10 \mathrm{hr}$ after inoculation; but the maximum $Q_{\mathrm{o}_{2}}$ values were somewhat lower (about 30-32; Fig. 2), and as the growth rate was much higher than that of the nocardia, these changes occurred earlier. The pseudomonad gave a similar result.

If the appearance of anthranilate oxidase in growing cultures is actually related to the presence of anthranilate in the medium, the corollary is that in the absence of this substrate, no anthranilate oxidase should develop. A possible reason for the decrease in the accumulation of anthranilate in the medium was given by observations that in shaking Warburg flasks where organisms were oxidising $o$-nitrobenzoate, and in shake cultures of Nocardia opaca growing on o-nitrobenzoate where aeration was very good, negligible accumulation of anthranilate occurred.

When the aeration rate of growing cultures of Nocardia opaca was raised from 2 to 5 and then to about 7 l. air/min. (anti-foam was necessary at these higher aeration rates when growth became appreciable) there was a substantial decrease in anthranilate accumulation and the enzyme did not form in such cultures (Table 1). The minimum concentration of anthranilate in the medium required to induce the enzyme was equivalent to about 5-6 $\mu \mathrm{g}$. anthranilic acid $/ \mathrm{ml}$. At 2-5 $\mu \mathrm{g}$. $/ \mathrm{ml}$. no formation of the oxidase was ever observed; above $8 \mu \mathrm{g} . / \mathrm{ml}$. the enzyme always appeared. Between the values 5-8 $\mu \mathrm{g} . / \mathrm{ml}$. the response was variable and the 
degree of maximal enzyme activity, when present, was usually low (i.e. $Q_{\mathrm{o}_{2}}$ of less than 15). The growth rate was near maximal with aeration rates of about 2 l. air/ min. and did not appreciably alter at higher rates; the variations in anthranilate production were thus not attributable to change in growth rate or yield.

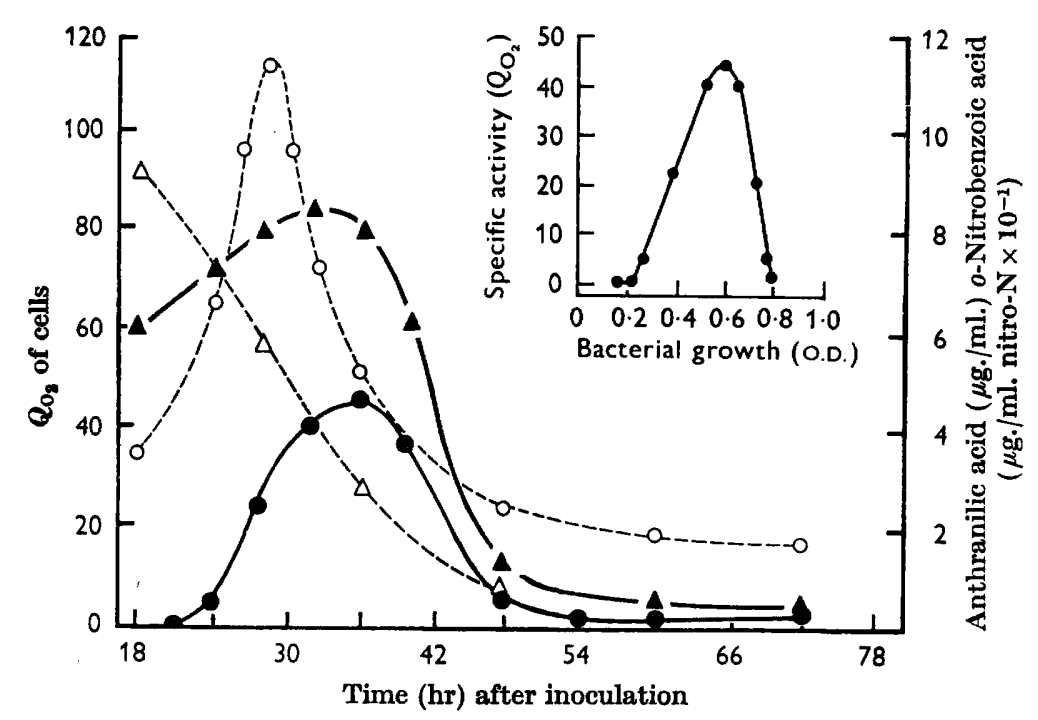

Fig. 1. Changes in enzyme activity with substrate concentration during growth of Nocardia opaca on o-nitrobenzoate. Enzyme activity represented by solid lines, substrate concentration by broken lines. $\Delta, 0$-nitrobenzoic acid; $O$, anthranilic acid; $\Delta, 0$-nitrobenzoate oxidizing system; 0 , anthranilate oxidase.

Inset. A plot of the 'differential rate of enzyme formation' (Monod, Pappenheimer \& Cohen-Bazire, 1952) for anthranilate oxidase from the same experiment.

Table 1. Effect of aeration rate on the anthranilic acid accumulation produced by Nocardia opaca in o-nitrobenzoate media

\begin{tabular}{|c|c|c|}
\hline $\begin{array}{l}\text { Aeration rate* } \\
\text { (air 1./min.) }\end{array}$ & $\begin{array}{l}\text { Mean observed } \\
\text { maximum } \\
\text { concentration of } \\
\text { anthranilic } \\
\text { acid }(\mu \mathrm{g} . / \mathrm{ml} .)\end{array}$ & $\begin{array}{l}\text { Anthranilate } \\
\text { oxidase formed }\end{array}$ \\
\hline 1 & $12 \cdot 3(5)$ & Yes \\
\hline 2 & $11 \cdot 7(20)$ & Yes \\
\hline $3 \cdot 5$ & $5 \cdot 5(7)$ & Variable \\
\hline 5 & $3 \cdot 8(3)$ & No \\
\hline 7 (approx.) & $2 \cdot 8(2)$ & No \\
\hline
\end{tabular}

Aeration rates were measured with a precision bore flowrator tube calibrated by and loaned from the Research Division of Continental Oil Company, Ponca City, Oklahoma, U.S.A.

The figures in parentheses in column 2 are the number of experiments done at this aeration rate.

\section{Some properties of the adaptive response}

Experiments were done with Nocardia opaca to examine the development of the anthranilate oxidizing system after addition of exogenous anthranilic acid (30 $\mu \mathrm{g}$. ml. final concentration) at $18 \mathrm{hr}$ to cultures growing on $o$-nitrobenzoate. From 
negligible amounts of the anthranilate oxidase at that time, there was a very rapid appearance of the enzyme system (sometimes up to 100-fold increase within 90 min.) but this appearance was completely prevented by the simultaneous addition of D-chloramphenicol ( $5 \mu \mathrm{g}$. $/ \mathrm{ml}$. final concentration) with the inducer (Fig. 3). At this concentration of chloramphenicol, growth still continued, but at about $20 \%$ of the normal rate; that is, the chloramphenicol appeared to inhibit preferentially the synthesis of induced enzyme as compared with general cell synthetic mechanisms. Such preferential inhibition of induced enzyme synthesis by chloramphenicol and some other antibiotics has been shown with the $\beta$-galactosidase

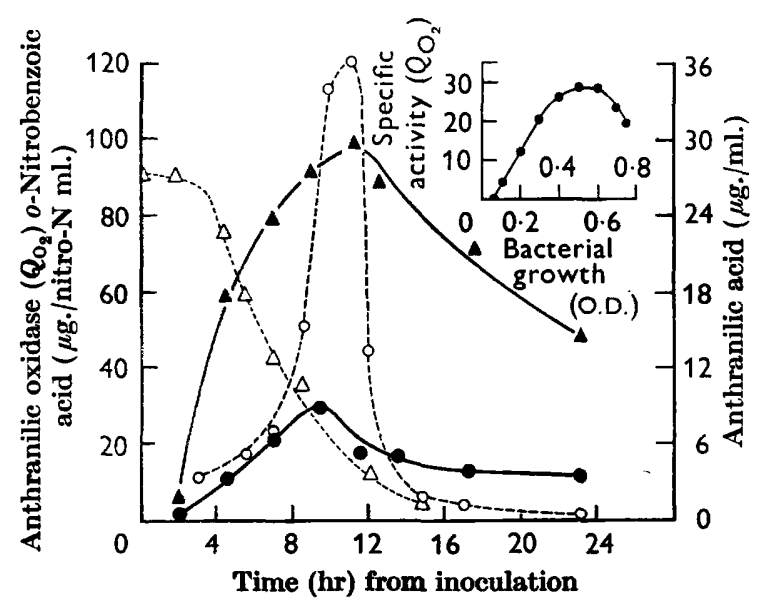

Fig. 2

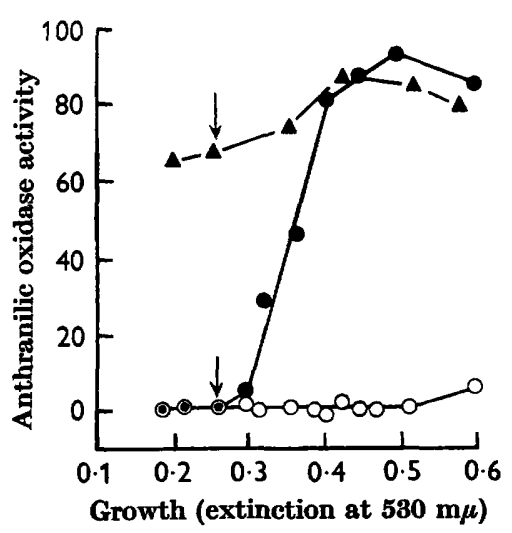

Fig. 8

Fig. 2. Changes in enzyme activity with substrate concentration during growth of a flavobacterium on 0 -nitrobenzoate. Symbols as in Fig. 1.

Inset. A plot of the 'differential rate of enzyme formation' for anthranilic oxidase in the flavobacterium from the same experiment.

Fig. 3. The induction of anthranilate oxidase in Nocardia opaca by exogenous anthranilate and its inhibition by chloramphenicol.

Three 5-l. cultures (two, $A$ and B, of o-nitrobenzoate and the third, $C$, of anthranilate media) were incubated for $18 \mathrm{hr}$. Sodium anthranilate (inducer; $90 \mathrm{mg}$. in $25 \mathrm{ml}$.) was then added to all three cultures (zero time) followed immediately by $100 \mathrm{ml}$. chloramphenicol to cultures $A$ and $C$ and $100 \mathrm{ml}$. water to culture $B$ (control). The final concentration of chloramphenicol in the media was $5 \mu \mathrm{g}$. $/ \mathrm{ml}$. Growth and anthranilate oxidase activity was followed in all three cultures.

The differential rate of anthranilic oxidase formation after adding inducer and $\boldsymbol{O}$, no antibiotic to $B$; $O$, + chloramphenicol to $A ; \boldsymbol{A}$, + chloramphenicol to $\mathrm{C}$. Inducer added at $(\downarrow)$.

system (Sypherd, Strauss \& Treffers, 1962), where the antibiotics act by inhibiting the inducer-promoted synthesis of messenger-RNA (Sypherd \& Strauss, 1963). Aronson \& Spiegelman (1961) showed, however, that D-chloramphenicol suppressed all protein synthesis when present in a sufficiently high concentration. Organisms previously grown in the presence of anthranilate, however, showed high values of anthranilate oxidase $\left(Q_{\mathrm{O}_{2}}\right.$ of 66) even after addition of chloramphenicol (Fig. 3). The 'differential rate of enzyme synthesis' (Monod, Pappenheimer \& Cohen-Bazire, 1952) was plotted, to exclude the possibility that the decreased rate of growth in 
the presence of D-chloramphenicol was responsible for the non-appearance of anthranilate oxidase in growing cultures. Chloramphenicol produced a genuine suppression of enzyme formation (Fig. 3).

\section{Metabolite induction}

The adaptive nature of the appearance of the anthranilate oxidase was confirmed in growing cultures of Nocardia opaca where D-chloramphenicol (5 $\mu \mathrm{g} . / \mathrm{ml}$.), but no exogenous anthranilic acid, was added at $24 \mathrm{hr}$. This concentration of chloramphenicol completely prevented the appearance of the self-induced anthranilate oxidase (Fig. 4) although the concentration of anthranilic acid (8.5 $\mu \mathrm{g} . / \mathrm{ml}$.) at

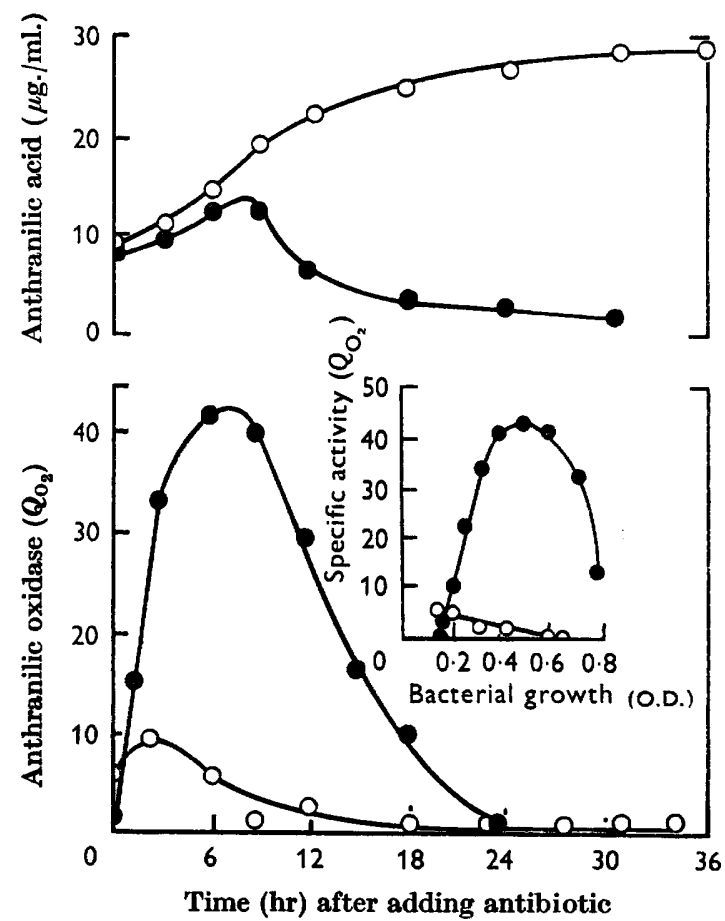

Fig. 4. Inhibition by chloramphenicol of the appearance of anthranilate oxidase induced by metabolically formed anthranilate. Chloramphenicol (final concentration $5 \mu \mathrm{g} . / \mathrm{ml}$.) was added to one of two similar 3-1. cultures of Nocardia opaca, incubated for 24 hr on o-nitrobenzoate medium. To the other culture was added water (control). Anthranilic acid concentrations in the medium, growth and anthranilate oxidase activities of the organisms were followed in both cultures.

The upper graph shows anthranilic acid concentrations in: 0 , control culture; $\bigcirc$, with chloramphenicol. The lower graph shows anthranilate oxidase values in: control culture; $O$, with chloramphenicol, in the same experiment.

The inset to the lower graph shows the differential rate of anthranilate oxidase formation: 0 , in the absence and $O$, in the presence of chloramphenicol, from the same experiment.

the time of antibiotic addition was quite sufficient to induce the enzyme (compare Fig. 1). A third culture containing L-chloramphenicol showed a response similar to that of the control experiment. In the absence of anthranilate oxidase in the $\mathrm{D}$ - 
chloramphenicol-treated culture there was no removal of accumulating anthranilic acid; the concentration of this metabolite therefore continued to increase to high values (25-30 $\mu \mathrm{g} . \mathrm{ml}$.) never attained with the nocardia under normal conditions. Calculation of the differential rate of enzyme formation showed that this was a true effect and not due to changes in growth rate. When bacteria from such a culture were now harvested aseptically, washed free from chloramphenicol and re-inoculated to fresh chloramphenicol-free medium at $30^{\circ}$ into which an amount of anthranilic acid equivalent to that existing in the original culture had been introduced, the anthranilate oxidase began to reappear within $2 \mathrm{hr}$ and the concentration of anthranilic acid then decreased rapidly. When $\mathrm{D}$-chloramphenicol (to $5 \mu \mathrm{g} . / \mathrm{ml}$.) was now again added to this fresh culture some $\mathbf{9 0}$ min. after induced anthranilate oxidase had appeared, further production of the enzyme ceased but the existing degree of activity was sufficient to prevent more accumulation of anthranilic acid.

\section{Table 2. The increase in the amounts of anthranilate oxidase in washed Nocardia opaca after the addition of various nitrogen sources}

Oxygen uptake per $15 \mathrm{~min}$. was measured at intervals from zero time to $3 \mathrm{hr}$ in duplicate experimental and one control flask for each of the additions, in the presence of excess sodium anthranilate. Control flasks contained no sodium anthranilate. During the $15 \mathrm{~min}$. period, the uptake was recorded every $3 \mathrm{~min}$. to compute $Q_{\mathrm{O}_{2}}$ values. Flasks contained: phosphate buffer (pH 7.0) $200 \mu$ moles; sodium anthranilate (side-arm), $100 \mu$ moles; washed suspension of organisms grown with o-nitrobenzoate, equiv. to $16.2 \mathrm{mg}$. dry-wt.; nitrogen source, $6 \mu$ moles, or in the case of Marmite, $12 \mathrm{mg}$. Chloramphenicol was added to $5 \mu \mathrm{g}$./ml. Incubation temp. $30^{\circ}$.

There was a very small increase in cell mass (about $3 \%$ ) during the experiment as shown by extinction measurements at zero time, $90 \mathrm{~min}$. and $3 \mathrm{hr}$.

\begin{tabular}{|c|c|c|c|}
\hline \multirow[b]{2}{*}{ Additions } & \multicolumn{3}{|c|}{$\begin{array}{c}\text { Increase in anthranilate } \\
\text { oxidase above zero time value* } \\
\text { at times shown (hr) }\end{array}$} \\
\hline & $\mathbf{1}$ & $\mathbf{2}$ & $\mathbf{3}$ \\
\hline None & 0 & 3.5 & 10.9 \\
\hline D-Chloramphenicol & $\mathbf{0}$ & $0 \cdot 3$ & 0.5 \\
\hline Ammonium sulphate & 0.7 & $\mathbf{5} \cdot \mathbf{2}$ & $11 \cdot 9$ \\
\hline L-Asparagine & $\mathbf{3} \cdot \mathbf{0}$ & $10 \cdot 0$ & $20 \cdot 2$ \\
\hline L-Asparagine $+\mathbf{D}$-chloramphenicol & 0 & $0 \cdot 6$ & $\mathbf{0 . 3}$ \\
\hline L-Glutamic acid & $\mathbf{5} \cdot \mathbf{2}$ & $13 \cdot 5$ & $\mathbf{3 5} \cdot \mathbf{6}$ \\
\hline L-Glutamic acid + D-chloramphenicol & $\mathbf{0}$ & 0.5 & $\mathbf{0 . 3}$ \\
\hline L-Glutamic acid + L-chloramphenicol & $5 \cdot 0$ & $12 \cdot 0$ & $\mathbf{3 3 - 0}$ \\
\hline Marmite (a yeast extract preparation) & 0 & 4.7 & $21 \cdot 9$ \\
\hline
\end{tabular}

* The zero time value for anthranilate oxidase in the eight experimental conditions was $0.6 \pm 0.3$.

Similar experiments were done with washed suspensions of Nocardia opaca harvested at times when the anthranilate-oxidizing activity was absent or minimal. The adaptation of these suspensions to added anthranilic acid again occurred in 90-120 min. but the rate of appearance and final amounts of enzyme were markedly increased in the presence of a nitrogen source (Table 2); L-glutamic acid gave the best results. There was only a very small increase in cell mass during these experiments. The induced anthranilate oxidase had an optimum in intact organisms at $\mathrm{pH} 7 \cdot 5$. 
The growth medium for these experiments contained yeast extract; ammonia also appeared as a metabolic product (Cain, 1958; Cartwright \& Cain, 1959 a). Both of these $\mathbf{N}$-sources might be held responsible for the rapid appearance of the anthranilate oxidase and the high concentrations of this enzyme which developed as the result of the metabolic production of anthranilic acid in growing cultures

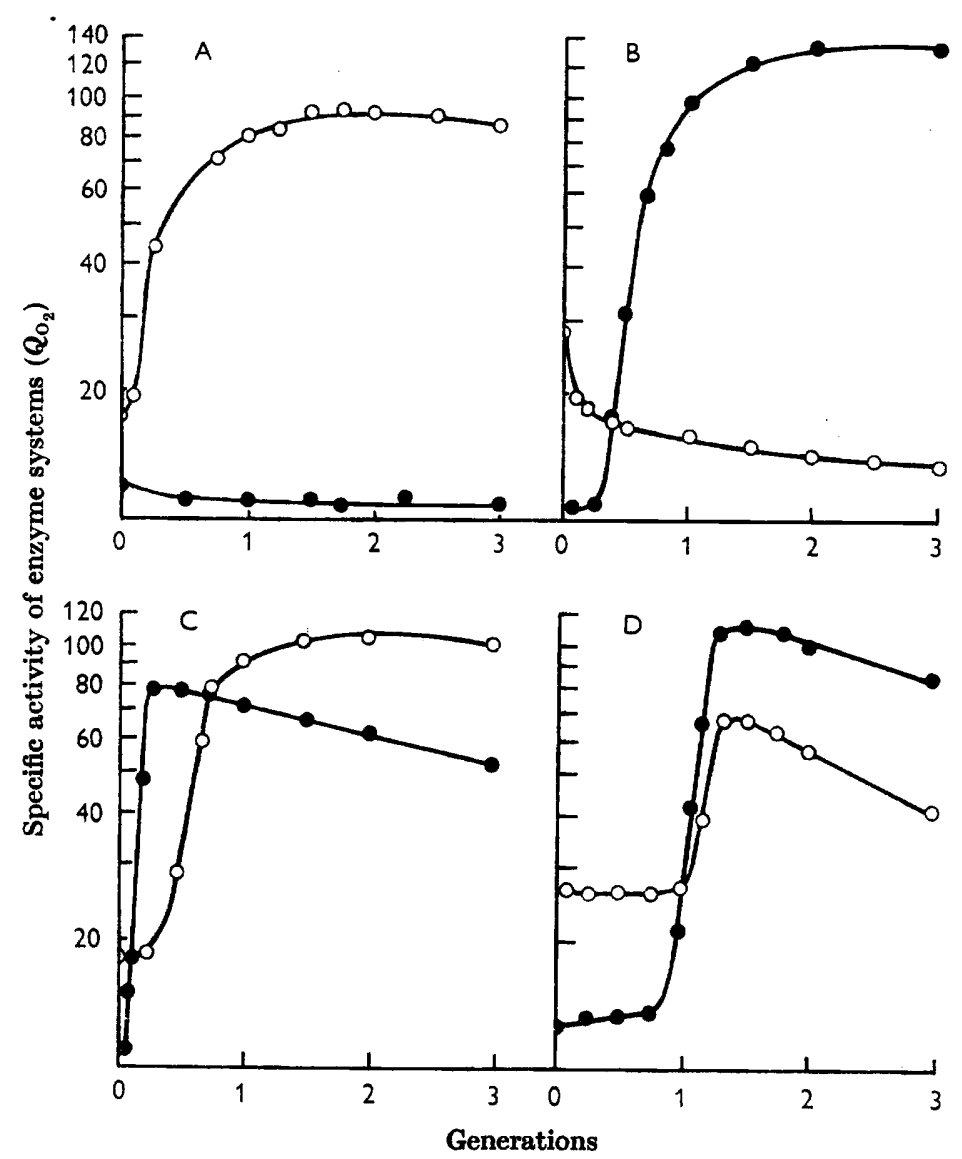

Fig. 5. Changes in enzyme content when Nocardia opaca was grown in different environments. Organisms were transferred aseptically from an o-nitrobenzoate culture (entering the stationary phase) to fresh medium containing: A: 10 mm-sodium o-nitrobenzoate; B: $10 \mathrm{~mm}$-sodium anthranilate; C: 5 mM-sodium anthranilate. Immediately after adaptation to anthranilate, sodium o-nitrobenzoate, to $5 \mathrm{~mm}$, was added; D: 2 mm-sodium o-nitrobenzoate +8 mM-sodium anthranilate. Growth and enzyme activity were followed as described in methods. 0,0 -nitrobenzoate oxidizing system; , anthranilate oxidase.

(see Fig. 1). An almost identical response, however, was given in minimal medium where both the $Q_{\mathrm{O}_{2}}$ of organisms oxidizing anthranilic acid and the concentrations of this metabolite formed from 0 -nitrobenzoic acid were similar to those found in Marmite-enriched media. 


\section{Variations in enzyme content with change of substrate}

The most convincing evidence for the truly inducible nature of the utilization of anthranilic acid was provided by experiments in which changes of enzyme content were measured in Nocardia opaca organisms transferred from o-nitrobenzoate medium to different regimens (compare Kornberg, Collins \& Bigley, 1960; Kornberg \& Morris, 1962). The results are shown in Fig. 5. When organisms from an $o$-nitrobenzoate culture just entering the stationary phase was transferred to fresh $o$-nitrobenzoate $(10 \mathrm{mM})$ medium, the specific activity of the 0 -nitrobenzoateoxidizing system increased some fourfold before one cell division, after a brief growth lag of less than $30 \mathrm{~min}$. and continued at this high level (Fig. 5A), whereas the anthranilate oxidase remained uniformly negligible throughout three generations. In contrast, transfer of $o$-nitrobenzoate-grown organisms to anthranilate $(10 \mathrm{mM})$ medium (containing no yeast extract) resulted in a growth lag of some 8-10 hr during which time there was a 50-fold increase of anthranilate oxidase in the organisms before growth began again. The amounts of the existing o-nitrobenzoate-oxidizing system decreased concomitantly (Fig. 5B).

In a third experiment (Fig. 5C) o-nitrobenzoate-grown organisms were transferred to $5 \mathrm{~mm}$-anthranilate medium. After adaptation to anthranilate had occurred (a 40-fold increase in anthranilate oxidase before one cell division) sodium $o$-nitrobenzoate was added to the culture to $5 \mathrm{~mm}$. There was an immediate increase in the o-nitrobenzoate-oxidizing system from the previously stationary value and concurrently with this increase a slow decrease in the amount of anthranilate oxidase.

When organisms were transferred from $o$-nitrobenzoate medium to fresh medium containing $2 \mathrm{~mm}-0$-nitrobenzoate $+8 \mathrm{~mm}$-anthranilate, the existing amounts of the $o$-nitrobenzoate-oxidizing system were maintained for the first generation while the nitrobenzoate substrate was being consumed (Fig. 5D). The anthranilate oxidase value also remained unchanged until near the end of this period but was followed by a rapid increase (17-fold) within half a generation. Chromatography of culture fluids showed that this enzyme increase occurred before the $o$-nitrobenzoate content of the medium was exhausted (at about 1.5 generations). Previous work has shown that $o$-nitrobenzoic acid and anthranilic acid are mutual competitive inhibitors of both growth and substrate oxidation in Nocardia opaca (Cain, 1966); growth and hence $o$-nitrobenzoic acid utilization in this experiment, where the initial ratio of $o$-nitrobenzoate to anthranilate concentrations was 1 to 4 , was consequently slow. The much smaller (two-fold) increase in the o-nitrobenzoate-oxidizing system occurred as the growth rate began to increase near the exhaustion of the $o$-nitrobenzoate in this system and immediately after the organisms had adapted to anthranilate. The reason for this small increase is not known but the sequence of events was consistent in media with and without yeast extract. The experiment provides additional evidence for the capacity of $N$. opaca to form adaptive enzymes to a new substrate even while an existing system is functioning; such a phenomenon is uncommon (Oda, Yamomoto \& Suda, 1951; Midgeley \& Hinshelwood, 1962) if not hitherto unknown (Spiegelman \& Dunn, 1947). 


\section{Inability of analogues to induce anthranilate oxidase}

The anthranilate oxidase of Nocardia opaca was induced in organisms grown with $o$-nitrobenzoate only by the metabolic formation of anthranilate and its accumulation in the medium, or by adding this substrate to growing cultures or washed suspensions. The enzyme was not induced in washed organisms within $8 \mathrm{hr}$ by $N$-methylanthranilicacid, 0 -aminobenzenesulphonic acid, 3-or 5-hydroxyanthranilic acids, 0 -aminophenol or benzoic acid, nor by 0 -nitrobenzoic acid itself. In washed suspensions derived from cultures grown on succinate, an identical picture was obtained.

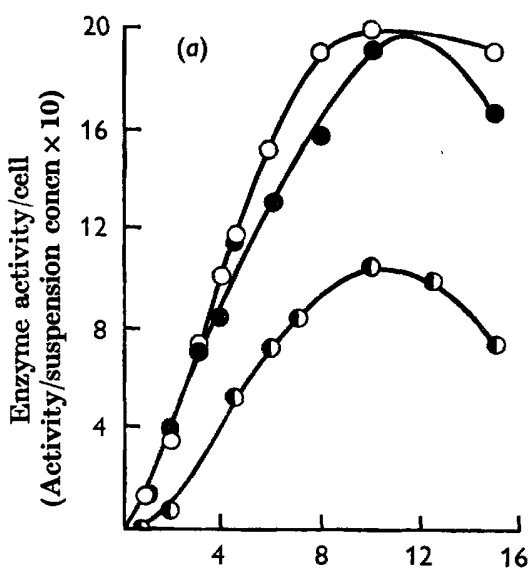

Time from addition of inducer (hr)

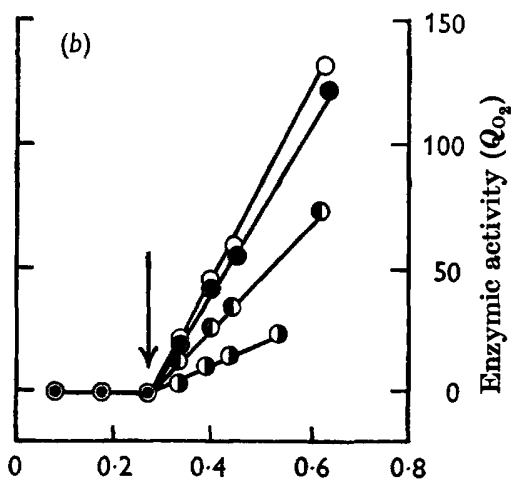

Growth (extinction at $580 \mathrm{~m} \mu$ )

Fig. 6. Annullment by $\mathrm{L}$-phenylalanine of the $p$-fluorophenylalanine inhibition of anthranilate oxidase formation in cultures of Nocardia opaca growing on o-nitrobenzoate.

(a) Three similar 5l. cultures were incubated for $12 \mathrm{hr}$. Sodium anthranilate (to $5 \mathrm{~mm}$ ) was added to all three cultures and then $p$-fluorophenylalanine (to $0.2 \mathrm{~mm}$ ) was added to one, $p$-fluorophenylalanine $(0.2 \mathrm{~mm})+\mathrm{L}$-phenylalanine $(1 \mathrm{~mm})$ to the second, and water (equivalent volume) to the third. Growth and anthranilate oxidase activity was then followed in each of the cultures. $O$, control culture (water added); $\ominus, p$-fluorophenylalanine + L-phenylalanine added; $\mathcal{O}, p$-fluorophenylalanine only added.

(b) Differential rate of anthranilate oxidase synthesis in four 51 . cultures of Nocardia opaca growing on 0 -nitrobenzoate. Anthranilic acid ( $5 \mathrm{~mm}$ ) was added where indicated by the arrow, and $O$, no additions; $O, p$-fluorophenylalanine $(0.2 \mathrm{~mm})+\mathrm{L}$-phenylalanine (1 mM); $\odot, p$-fluorophenylalanine ( $0.2 \mathrm{~mm})$ only; $O, p$-fluorophenylalanine $(0.5 \mathrm{~mm})$ only. In this experiment, the activity is recorded only during its increase; as in (a), amounts eventually fall. All concentrations represent final values in the culture medium.

\section{The effect of some inhibitors on induced enzyme formation}

As in growing cultures (Fig. 3) D-chloramphenicol at $5 \mu \mathrm{g} . / \mathrm{ml}$. or higher prevented the appearance of the anthranilate oxidizing system in washed suspensions of Nocardia opaca harvested from o-nitrobenzoate media, even in the presence of a stimulatory $\mathrm{N}$-source (Table 2); L-chloramphenicol had no such inhibitory effect. A complete failure to develop the enzyme in washed suspensions under such conditions was also caused by 1 or $5 \mathrm{~mm}$ - $p$-fluorophenylalanine and by $5 \mathrm{~mm}$ - (but not $1 \mathrm{~mm}), \beta$-2-thienylalanine. The fluorophenylalanine inhibition at $1 \mathrm{~mm}$ in these experiments was annulled by 2 mM-L-phenylalanine when added simultaneously 
with the inhibitor (compare Halvorson \& Spiegelman, 1952). The suppression of anthranilate oxidase induction by $0.2 \mathrm{~mm}-p$-fluorophenylalanine and its annullment by added L-phenylalanine (1.0 mM) was particularly evident in growing cultures of $N$. opaca (Fig. 6). Above 1.0 mM-p-fluorophenylalanine, growth was so slow that variations of enzyme activity with cell mass were difficult to measure.

Because synthesis of new enzyme protein is an energy-requiring process some general inhibitors of energy-producing systems (dinitrophenols, azide, arsenate; Monod, 1944; Reiner, 1946; Spiegelman, 1947; Monod \& Cohn, 1952; Cohen \& Monod, 1957) were examined for their effects upon anthranilate oxidase induction.

\section{Table 3. Inhibition by 2,4-dinitrophenol and sodium azide of the induction of anthranilate oxidase in washed Nocardia opaca grown on o-nitrobenzoate}

Incubation flasks contained: phosphate buffer (pH 7.0) 1 m-mole; bacterial suspension (equiv. to $184 \mathrm{mg}$. dry-wt.); anthranilic acid, added at zero time, $50 \mu$ moles; inhibitors to final concentrations as shown; water to total volume of $100 \mathrm{ml}$. These flasks were incubated at $30^{\circ}$ with shaking; 2 ml. samples were taken at intervals for determination of anthranilic oxidase and respiratory activity on 0 -nitrobenzoate (after centrifuging and washing the cells) as described in Methods.

\begin{tabular}{|c|c|c|c|c|c|}
\hline \multirow[b]{2}{*}{ Expt. } & \multirow[b]{2}{*}{ Inhibitor added } & \multirow{2}{*}{$\begin{array}{c}\text { Concentration } \\
\text { (mM) }\end{array}$} & \multicolumn{3}{|c|}{ time $(\mathrm{hr})$} \\
\hline & & & 0 & 2 & 4 \\
\hline \multirow[t]{8}{*}{1} & None & 一 & $1.5(190)$ & $4 \cdot 0(130)$ & $20.5(105)$ \\
\hline & 2,4-Dinitrophenol & 0.01 & $1.5(195)$ & $5 \cdot 0(130)$ & $22 \cdot 0(110)$ \\
\hline & & $0 \cdot 1$ & $1.5(195)$ & $3.9(135)$ & $20 \cdot 0(100)$ \\
\hline & & $0 \cdot 2$ & $1.5(180)$ & $3.7(120)$ & $14 \cdot 3(94)$ \\
\hline & & 0.5 & $1.5(160)$ & $3 \cdot 2(122)$ & $7 \cdot 0(85)$ \\
\hline & & $0 \cdot 8$ & $1.5(130)$ & $2.5(94)$ & $4.0(60)$ \\
\hline & & $1 \cdot 0$ & $1.5(80)$ & $2.5(32)$ & $4.0(20)$ \\
\hline & & $5 \cdot 0$ & $1 \cdot 5(45)$ & $0 \quad(10)$ & $0 \quad(0)$ \\
\hline \multirow[t]{5}{*}{2} & None & - & $2 \cdot 3(210)$ & $7 \cdot 0(165)$ & $20.5(100)$ \\
\hline & Sodium azide & $0 \cdot 1$ & $2 \cdot 3(213)$ & $9 \cdot 3(160)$ & $20 \cdot 8(88)$ \\
\hline & & 0.5 & $2 \cdot 3(200)$ & $4.5(150)$ & $12.8(90)$ \\
\hline & & $\mathbf{2 \cdot 0}$ & $2 \cdot 3(173)$ & $3 \cdot 8(158)$ & $7 \cdot 8(80)$ \\
\hline & & $\mathbf{3} \cdot \mathbf{0}$ & $2 \cdot 3(190)$ & $2 \cdot 1(148)$ & $3 \cdot 0(75)$ \\
\hline
\end{tabular}

Amounts of anthranilate oxidase and respiration rate ( $\mu \mathrm{l}$./hr on 0 -nitrobenzoate) after addition of inducer at zero time time (hr)

The figures in parentheses are the initial oxygen uptakes on 0 -nitrobenzoate ( $3 \mu$ moles) corrected for endogenous respiration at the same inhibitor concentration.

2,4-Dinitrophenol at $0.1 \mathrm{~mm}$ was without effect on the induction of anthranilate oxidase in washed suspensions of Nocardia opaca, but at $5 \mathrm{~mm}$ it completely suppressed such induction and markedly decreased the respiration of washed organisms on $o$-nitrobenzoate. At intermediate concentrations of 2,4-dinitrophenol $(0 \cdot 2-0 \cdot 8$ $\mathrm{mM})$, the adaptive response was suppressed without significantly depressing the respiration on $o$-nitrobenzoate; a similar result was given by 2 and 3 mM-sodium azide (Table 3). The decrease in respiration rate of the samples after increasing incubation times in the absence of $o$-nitrobenzoate was examined in the experiments on 'de-adaptation' (see Fig. 8 and later).

The anthranilic acid analogues $N$-methylanthranilic acid and $o$-aminobenzenesulphonic acid also decreased growth upon, and inhibited oxidation of, anthranilic and $o$-nitrobenzoic acids by Nocardia opaca and the flavobacterium (Cain \& 
Durham, unpublished). $N$-Methylanthranilate, although without appreciable effect on the amounts of anthranilate which accumulated in 5 l. cultures of $N$. opaca growing on 0 -nitrobenzoate, strongly suppressed the induction of anthranilate oxidase by this metabolite (Fig. 7).

Induction of the anthranilate oxidase in washed organisms was prevented by u.v. irradiation of the suspension and no induction took place when organisms were incubated with the inducer in anaerobic $\left(\mathrm{N}_{2}\right.$ or $\left.\mathrm{H}_{2}\right)$ atmospheres.

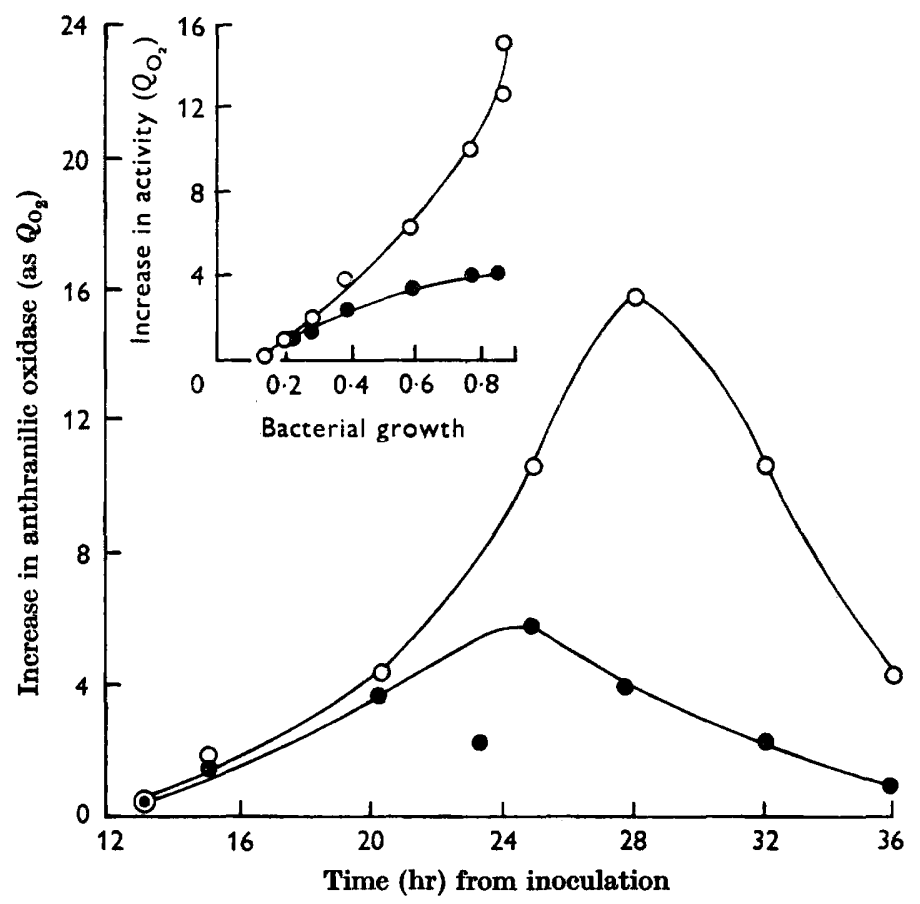

Fig. 7. The effect of $N$-methylanthranilic acid on induction of anthranilate oxidase in Nocardia opaca growing on 0 -nitrobenzoate.

Two similar $8 \mathrm{l}$. cultures of $N$. opaca were incubated at $30^{\circ}$ for $12.75 \mathrm{hr}$ after inoculation, and samples of each taken for measurement of growth and anthranilate oxidase activity. To one culture was added $N$-methylanthranilic acid solution (adjusted to $\mathrm{pH} 7 \cdot 0$ ) to final concentration $4 \mathrm{~mm}$; an equivalent volume of distilled water was simultaneously added to the other (control). Growth and anthranilate oxidase activity measurements were continued at intervals thereafter. $O$, Anthranilate oxidase increase in control culture; , anthranilate oxidase increase in culture treated with $N$-methylanthranilate.

Inset. Increase in enzyme activity plotted as a function of growth. (Increases in enzyme activity above that at $12.75 \mathrm{hr}$ were used here to show the effect of the inhibitor more clearly. At this time, just before the addition of inhibitor, the actual values of existing anthranilate oxidase $\left(Q_{\mathrm{O}_{2}}\right)$ were 7.8 in the control culture and 10.3 in the experimental culture.)

\section{Additional evidence for the inducible nature of the anthranilate oxidase in Nocardia opaca}

The features of the appearance of anthranilate oxidase so far described are those characteristic of induced enzyme synthesis in response to the presence of an inducer but the possibility remained that some of the observations made with growing cultures were the result of the rapid selection of existing mutants. The 
ability of organisms grown on $o$-nitrobenzoate to utilize anthranilate was therefore examined by the fluctuation test and by a replica plating technique (see Methods).

In the fluctuation test, the contents of the $1 \mathrm{ml}$. tubes and $1 \mathrm{ml}$. samples of the $15 \mathrm{ml}$. cultures were plated on anthranilate medium (containing no yeast extract) incubated at $30^{\circ}$ and inspected at regular intervals. There was no growth at $24 \mathrm{hr}$ or $36 \mathrm{hr}$ but at $48 \mathrm{hr}$, and subsequently, generalized background growth occurred

Table 4. Anthranilate-utilizing colonies developing from samples of a single $15 \mathrm{ml}$. culture and from samples taken from a series of independent $1 \mathrm{ml}$. cultures of Nocardia opaca growing for $18 \mathrm{hr}$ on o-nitrobenzoate defined medium and containing $94 \cdot \times 10^{4}$ organisms/ml.

Number of colonies developing on anthranilic acid defined medium

Samples from single $15 \mathrm{ml}$. culture

$\begin{array}{cccc}\text { Sample no. } & \text { No. of colonies } & \text { Sample no. } & \text { No. of colonies } \\ 1 & 131 & 8 & 152 \\ 2 & 123 & 9 & 145 \\ 3 & 130 & 10 & 129 \\ 4 & 129 & 11 & 83 \\ 5 & 112 & 12 & 114 \\ 6 & 120 & 13 & 127 \\ 7 & 225 & 14 & 124 \\ & \text { Mean } & 131 \cdot 7 & \\ & \text { Variance } & 905 \cdot 6 & \\ & \text { X-square } & 6 \cdot 87 & \\ & P \text { (approx.) } & 0 \cdot 91 & \end{array}$

Samples from independent $1 \mathrm{ml}$. cultures

\begin{tabular}{cccc}
\hline Culture & No. of colonies & Culture & No. of colonies \\
1 & 117 & 8 & 123 \\
2 & 120 & 9 & 161 \\
3 & 102 & 10 & 116 \\
4 & 153 & 11 & 80 \\
5 & 180 & 12 & 97 \\
6 & 115 & 13 & 105 \\
7 & 127 & 14 & $65^{*}$ \\
& Mean & $119 \cdot 8$ & \\
& Variance & $478 \cdot 0$ & \\
& $\mathcal{X}$-square & $4 \cdot 06$ & \\
& P (approx.) & $0 \cdot 98$ & \\
& &
\end{tabular}

* This sample was splashed with condensed water from the lid of the Petri dish and was not used in the calculations.

on the anthranilate medium . This was the response to be expected if organisms grown with 0 -nitrobenzoate acid were uniformly adapting to utilize anthranilate. In a second experiment where the tube contents were plated before visible growth was evident (18-hr incubation at $30^{\circ}$ ), measurable numbers of small colonies were observable after incubation for $40 \mathrm{hr}$ on the anthranilate medium; the results of this experiment, read at $48 \mathrm{hr}$, are shown in Table 4. All the colonies which eventually appeared, developed at approximately the same time after plating. The similarity of the means and the high values for $P$ of 0.98 , and 0.91 , for independent cultures and samples of a single culture, respectively, showed that mutational 
effects were unlikely to have been responsible for the appearance of mutants which oxidized anthranilate.

Replicas (Lederberg \& Lederberg, 1952) from master plates of about 150 microcolonies of Nocardia opaca, growing on 0 -nitrobenzoate medium, were made on plates of anthranilate, salicylate, benzoate and $p$-hydroxybenzoate media and on a control plate of 0 -nitrobenzoate medium. There was a lag of some $36 \mathrm{hr}$ before any

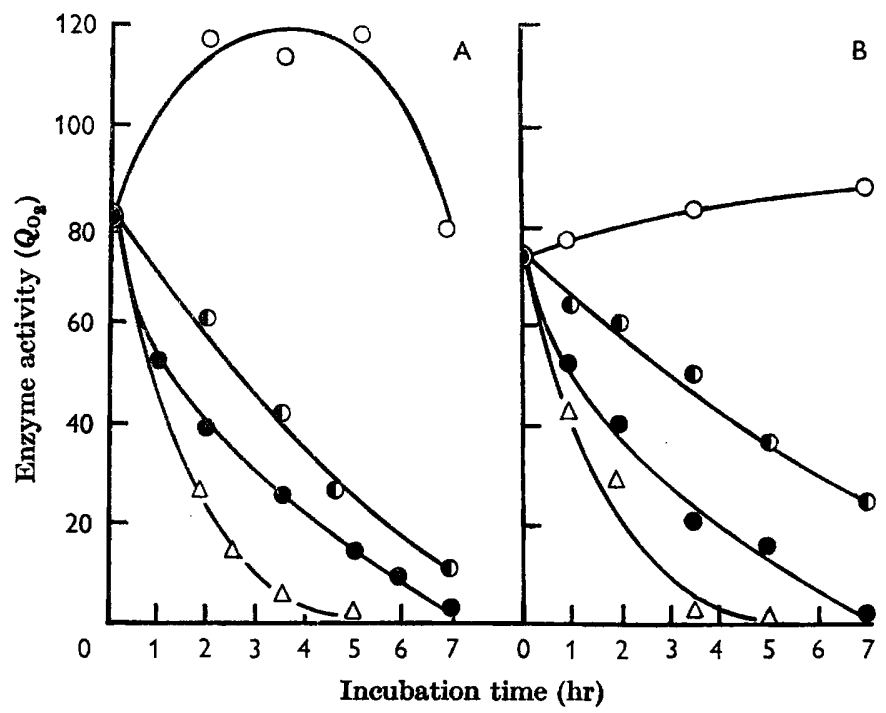

Fig. 8. Loss of enzyme activity by Nocardia opaca in the absence of substrate. Incubation flasks contained: phosphate buffer ( $\mathrm{pH}$ 7.0) 2.5 m-moles; suspension of organisms originally grown on either 0 -nitrobenzoate (A) or anthranilate (B) medium; additions as shown. Total volume, $50 \mathrm{ml}$. Flasks were incubated at $30^{\circ}$ and $37^{\circ}$ in a metabolic shaking bath (throw, $3 \mathrm{~cm}$; 136 strokes/min.) and $5 \mathrm{ml}$. samples withdrawn at hourly intervals for manometric determinations of enzyme activity in the organisms (see Methods). For (A), Warburg flasks contained equiv. 1.40 mg. dry-wt. organisms; for (B), 1.30 mg. drywt. organisms.

A. Loss of the $\theta$-nitrobenzoate oxidizing system in the presence of: $O$, sodium 0 -nitrobenzoate $(10 \mathrm{mM})$ at $30^{\circ} ; \mathrm{D}$, sodium anthranilate $(10 \mathrm{mM})$ at $30^{\circ} ; \circ$, no addition at $30^{\circ}$; $\triangle$, no addition at $37^{\circ}$.

B. Loss of anthranilate oxidase in the presence of: $O$, sodium anthranilate at $30^{\circ}$; $D$, sodium $o$-nitrobenzoate at $30^{\circ} ; 0$, no addition at $30^{\circ} ; \triangle$, no addition at $37^{\circ}$.

growth appeared on these media (except on 0 -nitrobenzoate where visible colonies were evident at $24 \mathrm{hr}$, and on salicylate where no growth took place). After the growth lag, every colony on the master-plate was reproduced in the other media which supported growth, suggesting that such growth resulted from adaptation to the new substrates. In only 150 original organisms per master plate, the presence of mutants is unlikely if it be assumed that true mutation to anthranilate utilization occurred in the usual proportion of 1 in $10^{7}$ to 1 in $10^{8}$. When the master plate inoculum was increased to give between $10^{8}$ and $10^{\circ}$ organisms, general background growth took place after a 36-hr lag on the replica plates. There was no indication in any of many repeated experiments of the development of anthranilate utilizing mutants which should have shown preferential growth when plated on anthranilate medium. 


\section{De-adaptation}

The loss of an enzyme after removal or disappearance of the inducer has been termed 'enzymic de-adaptation'; such loss of enzyme activity, upon exhaustion of the specific substrate, was consistently observed in Nocardia opaca. The rates of disappearance of both the $o$-nitrobenzoate-oxidizing system and the self-induced anthranilate oxidase in $N$. opaca were measured under different conditions in the absence of a readily metabolized nitrogen source. Figs. $8 \mathrm{~A}$ and $\mathrm{B}$ show the marked loss in enzyme activity observed in the absence of the inducer, particularly at $37^{\circ}$. Addition of chloramphenicol did not appreciably decrease the rate of loss of enzyme, but addition of the specific inducer maintained or increased the amounts of enzyme. An unusual feature observed in experiments with the o-nitrobenzoate-oxidizing system and with the induced anthranilate oxidase was the slower rate of enzyme loss when an analogue of the inducer was present. Anthranilate decreased the rate of loss of the 0 -nitrobenzoate system by about $40 \%$ over the first $2-3 \mathrm{hr}$ of the experiments; 0 -nitrobenzoate inhibited the loss of the anthranilate oxidase by some $30 \%$ over the same period. This increased maintenance of amounts of enzyme in the presence of analogues as distinct from true substrates recalls the inducing ability of fluorobenzene analogues in benzoic acid metabolism by Pseudomonas fluorescens (Hughes, 1953) where it was suspected that the analogue combined with a receptor to form an inducing complex, similar to that formed with the natural substrate; such a reaction was envisaged by Pollock (1953).

\section{DISCUSSION}

Adaptive enzyme formation (enzyme induction) is the term generally used to describe the synthesis of new enzyme under the influence of a specific exogenous inducer. A special case of enzymic induction is the phenomenon of 'sequential induction' (Stanier, 1947) which includes the enzyme induced by, and acting on, the added substrate together with all the enzymes induced by the successive intermediary metabolites along a metabolic route. In sequential induction it is usual to regard the inducer-metabolite as remaining within the organism, but in the present instance the inducer has to leave the cell and accumulate in the medium to above a threshold value before enzyme induction occurs. The expression 'metabolite-induced' has therefore been used to distinguish between anthranilate oxidase induction by anthranilate metabolically formed from 0 -nitrobenzoate, and induction by added (exogenous) anthranilate. A similar phenomenon has been observed in the 'aromaticless' mutant Y7655 of Neurospora crassa which is blocked after dehydroshikimic acid; this mutant accumulates dehydroshikimic acid and converts it to protocatechuic acid which can be detected in the medium. Such mutants always show high values of protocatechuic acid oxidase (Gross, Gafford \& Tatum, 1956) induced by this by-product of their own metabolism, whereas the wild type requires added protocatechuic acid or vanillic acid to induce this enzyme. The accumulation of enzyme inducer in this case with neurospora, shunts the products of a biosynthetic pathway into the constitutive pathway of energy-yielding reactions via two catabolic sequences previously not used to a significant extent (Gross, 1959). Similarly, in the present study with Nocardia opaca, the by-product of a secondary 
reaction (reduction of $o$-nitrobenzoate to anthranilate) may be utilized in an energyyielding process.

Another feature in which the present system resembles the classical sequential induction response is the ease of 'de-adaptation' on exhaustion or removal of the specific inducer. Enzyme values of $o$-nitrobenzoate and anthranilate oxidation in nocardia began to decrease almost immediately on removal of the inducer substrates. For the experiment recorded in Fig. 8, the time between harvesting the organisms and their suspension in the buffer systems (zero time) was about $20 \mathrm{~min}$.; loss of enzyme was rapid from zero time onwards. Because these changes took place under conditions of non-proliferation of the organisms, it may be assumed that loss of activity was due to actual breakdown of the adaptive enzymes (Spiegelman, 1950; Robertson \& Halvorson, 1957) rather than by diluting out (Wainwright \& Pollock, 1949; Rickenberg, Yanofsky \& Bonner, 1953). It is unlikely that cell death or enzyme inactivation were responsible for the losses in activity because recovery of activity could be shown, after the usual time lag, simply by adding more of the specific inducer.

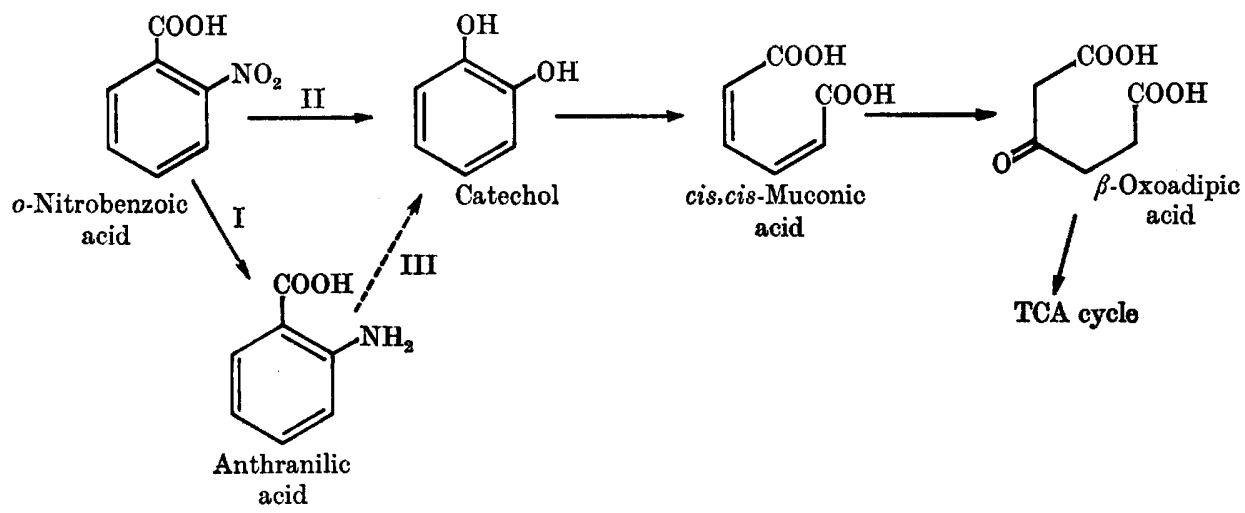

Fig. 9. Initial steps in the metabolism of $o$-nitrobenzoic acid and anthranilic acid by Nocardia opaca.

Metabolite induction in Nocardia opaca provides further evidence that anthranilic acid is not an obligatory intermediate on the pathway of the aerobic metabolism of $o$-nitrobenzoic acid by this organism. A similar situation also appears to exist in the flavobacterium strain used where the amounts of anthranilate oxidase were drastically de-creased by chloramphenicol and also varied with the marked changes in anthranilate concentration which occurred during its growth in $o$ nitrobenzoate medium. If anthranilic acid were an obligatory direct intermediate in $o$-nitrobenzoic acid degradation, the absence of anthranilate oxidase should lead to a complete block in the ability of the organism to grow, because this enzyme is responsible for conversion of its substrate to catechol, the intermediate which is ultimately degraded to the aliphatic products utilized for energy production and cell carbon (Hayaishi \& Stanier, 1951; Higashi \& Sakamoto, 1960). It is known that in Nocardia opaca both anthranilic and $o$-nitrobenzoic acids are separately metabolized through catechol (steps II and III, Fig. 9; Cain \& Cartwright, 1960 $a$; Cain, 1966); a route for 0 -nitrobenzoate breakdown through catechol is thus followed 
whether anthranilic acid is regarded as an intermediate in 0 -nitrobenzoic acid metabolism or not. In the absence of anthranilate oxidase, the reduction step (I) is the only known reaction which could occur when 0 -nitrobenzoic acid is the substrate. Energy considerations (reduction of the nitro group is NADH-mediated Saz \& Slie, 1954; Cartwright \& Cain, 1959b; formation of NADH usually requires, not yields, energy) and molar growth yield experiments with anthranilic and $o$ nitrobenzoic acids as substrates (Cain, 1966) suggest that no energy is available from this reduction step. Since growth does occur in the normal absence of the anthranilate oxidase enzyme (Fig. $5 \mathrm{~A}$ ) and when its formation is inhibited (Figs. 3, 6 and 7 ), the conclusion must be that anthranilate cannot be an obligatory intermediate in the energy-producing pathway of $o$-nitrobenzoate metabolism and that, for energy requirements, 0 -nitrobenzoate is degraded to catechol either directly or via some alternate route not involving initial reduction.

The use of whole organisms in these experiments is open to the criticism that permeability effects may have operated, i.e. the response measured may have been that of the induction of a specific transport mechanism for anthranilate rather than of a new intracellular enzyme. Experiments with organisms slowly dried in air (compare Sleeper, Tsuchida \& Stanier, 1950) and with detergent-treated organisms where the permeability barrier has been destroyed (Cain, 1966) indicate that this is not the case. Experiments with (carboxyl-14 $\mathrm{C}$ )-anthranilic acid have shown that whole organisms grown on o-nitrobenzoate or succinate media, only accumulate anthranilate very slowly before adaptation occurs, whereas organisms originally grown on anthranilate rapidly take up and oxidize added anthranilate; both these processes are inhibited by o-nitrobenzoic acid (Cain, 1966). Organisms from nitrobenzoate cultures, metabolite-induced by anthranilate, or from such cultures to which anthranilate has been added, have similar rates of anthranilate accumulation and oxidation as those originally grown on anthranilate. If a transport system is involved in anthranilate metabolism therefore, it must be metaboliteinduced and lost under the same conditions as is the 'oxidase'.

Parts of this work were done during the tenure of an Imperial Chemical Industries Fellowship at the University of Leeds. It was completed at Oklahoma State University under a project awarded to Dr N. N. Durham by the National Science Foundation (GB-166).

\section{REFERENCES}

Aronson, A. I. \& Spiegelman, S. (1961). Protein and ribonucleic acid synthesis in a chloramphenicol-inhibited system. Biochim. Biophys. Acta, 53, 70.

Barnett, J. A. \& Ingram, M. (1955). Technique in the study of yeast assimilation reactions. J. appl. Bact. 18, 131.

Carn, R. B. (1958). The microbial metabolism of nitro-aromatic compounds. J. gen. Microbiol. 19, 1.

CAIN, R. B. (1966). Utilization of anthranilic and nitrobenzoic acids by Nocardia opaca and a flavobacterium. J. gen. Microbiol. 42, 219.

CaIN, R. B. \& Cartwright, N. J. (1960a). On the properties of some aromatic ringopening enzymes of species of the genus Nocardia. Biochim. Biophys. Acta, 37, 197.

CaIn, R. B. \& Cartwright, N. J. (1960b). Intermediary metabolism of nitro-benzoic acids by bacteria. Nature, Lond. 185, 868.

Cartwright, N. J. \& Cain, R. B. (1959 $a$ ). Bacterial degradation of the nitrobenzoic acids. Biochem. J. 71, 248. 
Cartwright, N. J. \& Cain, R. B. (1959b). Bacterial degradation of the nitrobenzoic acids. 2. Reduction of the nitro group. Biochem. J. 73, 305.

Cohen, G. N. \& Monod, J. (1957). Bacterial permeases. Bact. Rev. 21, 196.

Durham, N. N. (1958). Studies on the metabolism of $p$-nitrobenzoic acid. Can. J. Microbiol. $4,141$.

Grazko, A. J., Wolf, L. M. \& Dill, W. A. (1949). Biochemical studies on chloramphenicol. I. Colorimetric methods for the determination of chloramphenicol and related nitrocompounds. Arch. Biochem. 23, 411.

Gross, S. R. (1959). Enzymatic autoinduction and hypothesis of intracellular permeability barriers in Neurospora. Trans. N.Y. Acad. Sci. 22, 44.

Gross, S. R., Gafford, R. D. \& TATUM, E. L. (1956). The metabolism of protocatechuic acid by Neurospora. J. biol. Chem. 219, 79.

Halvorson, H. O. \& Spiegelman, S. (1952). The inhibition of enzyme formation by amino acid analogues. J. Bact. 64, 207.

Hayaishi, O. \& Stanier, R. Y. (1951). Bacterial oxidation of tryptophan. III. Enzymatic activities of cell-free extracts from bacteria employing the aromatic pathway. J. Bact. 62,691 .

Hrgashi, T. \& Sakamoto, Y. (1960). Oxidation of anthranilic acid catalysed by Pseudomonas cell-free extract. J. Biochem. (Japan), 48, 147.

Hughes, D. E. (1953). In Adaptation in Micro-organisms. Symp. Soc. Gen. Microbiol. 3, 147.

Ke, Y-H., GeE, L. L. \& Durham, N. N. (1959). Mechanism involved in the metabolism of nitrophenyl-carboxylic acid compounds by micro-organisms. J. Bact. 77, 593.

KornBerg, H. L. \& Morris, J. G. (1962). The influence of growth substrates on oxaloacetate formation from $\beta$-hydroxyaspartate by Micrococcus denitrificans. Biochim. Biophys. Acta, 65, 378.

Kornberg, H. L., Coluins, J. F. \& Bigley, D. (1960). The influence of growth substrates on metabolic pathways in Micrococcus denitrificans. Biochim. Biophys. Acta, 39, 9.

LeDERBERG, J. \& LeDERBERg, E. M. (1952). Replica plating and indirect selection of bacterial mutants. J. Bact. $63,399$.

LuRIA, S. E. \& Delbrück, M. (1943). Mutations of bacteria from virus sensitivity to virus resistance. Genetics, 28, 491.

Midgeley, J. E. M. \& Hinshelwoon, C. (1962). The stability of an adaptive enzyme formed during growth of Bact. lactis aerogenes (Aerobacter aerogenes) in D-arabinose. II. Reversion phenomena. Proc. roy. Soc., B. 155, 384.

MonoD, J. (1944). Inhibition de l'adaptation enzymatique chez $B$. coli en presence de 2,4-dinitrophénol. Ann. Inst. Pasteur, 70, 381.

MonoD, J. \& CoHN, M. (1952). La biosynthèse induite des enzymes (adaptation enzymatique). Advanc. Enzymol. 13, 67.

Monod, J., Pappenheimer, A. M. Jun., \& Cohen-Bazire, G. (1962). La cinétique de la biosynthèse de la $\beta$-galactosidase chez $E$. coli considérée comme fonction de la croissance. Biochim. Biophys. Acta, 9, 648.

OdA, Y., YAMAMOTo, Y. \& SUdA, M. (1951). Studies on mechanism of enzymatic adaptation with special reference to the relation between the formation of adaptive enzymes and phosphate metabolism. Med. J. Osaka Univ. 2, 125.

Pollock, M. R. (1953). Stages in enzyme adaptation. In Adaptation in Micro-organisms. Symp. Soc. gen. Microbiol. 3, 150.

ReINER, J. M. (1946). Effect of enzyme inhibitors on transformations of enzymes in the living cell. Proc. Soc. exp. Biol. Med. 63, 81.

Rickenterg, H. V., Yanofsky, C. \& Bonner, D. M. (1953). Enzymatic deadaptation. J. Bact. 66, 683 .

Robertson, J. J. \& Halvorson, H. O. (1957). The components of the maltozymase in yeast, and their behaviour during deadaptation. J. Bact. 73, 186.

SAZ, A. K. \& SLIE, R. B. (1954). The inhibition of organic nitro reductase by aureomycin in cell-free extracts. II. Cofactor requirements for the nitro reductase enzyme complex. Arch. Biochem. Biophys. 51, 5. 
SLeEPer, B. P., Tsuchida, M. \& Stanier, R. Y. (1950). The bacterial oxidation of aromatic compounds. II. The preparation of enzymatically active dried cells, and the influence thereon of prior patterns of adaptation. J. Bact. 59, 129.

Spiegelman, S. (1947). The dissociation of anaerobic metabolism from enzymatic adaptation in yeast. J. cell. comp. Physiol. 301, 315.

SPIEGELMAN, S. (1950). Modern aspects of enzymatic adaptation. In The Enzymes, Vol. 1, Pt. 1, p 167. Ed. by J. B. Summer and K. Myrback. New York: Academic Press, Inc.

SpIEgelman, S. \& DUNN, R. (1947). Interaction between enzyme forming systems during adaptation. J. gen. Physiol. 31, 153.

STANIER, R. Y. (1947). Simultaneous adaptation: a new technique for the study of metabolic pathways. J. Bact. 54, 339.

Sypherd, P. S. \& Strauss, N. (1963). Chloramphenicol-promoted repression of $\beta$-galactosidase synthesis in Escherichia coli. Proc. natn Acad. Sci., U.S.A. 49, 400.

Sypherd, P. S., Strauss, N. \& Treffers, H. P. (1962). The preferential inhibition by chloramphenicol of induced enzyme synthesis. Biochem. Biophys. Res. Comm. 7, 477.

Taniuchi H., Hatanaka, M., Kuno, S., Hayaishi, O., Nakajima, M. \& Kurihara, N. (1964). Enzymatic formation of catechol from anthranilic acid. J. biol. Chem. 239, 2204.

Wainwright, S. D. \& Pollock, M. R. (1949). Enzyme adaptation in bacteria: fate of nitratase in nitrate-adapted cells grown in the absence of substrate. Br. J. exp. Path. 30, 190. 